\title{
Incoordinate left ventricular wall motion after acute myocardial infarction Serial echocardiographic assessment
}

\author{
J R DAWSON, * G C SUTTON \\ From the Cardiac Department, Hillingdon Hospital, Uxbridge, Middlesex
}

SUMMARY Serial simultaneous $M$ mode echocardiograms, phonocardiograms, and apexcardiograms were recorded and digitised in 20 patients with a first myocardial infarction immediately after and two, three, seven, and 56 days after hospital admission. Left ventricular maximum and minimum dimensions, normalised maximum rate of change of dimension during systole and diastole, and three previously defined indices of the coordination of left ventricular wall motion were measured.

Incoordinate left ventricular wall motion was detected in all patients but was more pronounced in those with an anterior infarction (15) than in those with an inferior infarction (5). Although on the first three days after admission patients with heart failure (7) were indistinguishable echocardiographically from those without (13), differences became apparent later with an increase in left ventricular dimension and more pronounced evidence of incoordination in those with heart failure. In the first two days after admission patients with full thickness infarcts (14) were indistinguishable echocardiographically from those with partial thickness infarcts (6) despite the former being of much larger size as judged by the measurement of cardiac enzyme activity. Abnormal indices of coordination reverted to normal with time in patients with partial thickness infarctions, whereas only partial reversion of these indices occurred in those with full thickness infarctions.

The use of digitised $M$ mode echocardiograms is a sensitive means of detecting and following the evolution of incoordinate left ventricular wall motion in patients with an acute myocardial infarction whatever the position, type, or size of the infarct. Incoordination so detected is, however, quantitatively unrelated to infarct type or size or to the clinical state of the patient.

Myocardial infarction causes abnormalities of left ventricular wall motion. Reduced amplitude of endocardial motion and abnormal wall thinning are both well recognised features and may be identified noninvasively using $M$ mode $^{1} 2$ or cross sectional echocardiography. ${ }^{34}$

Another less well recognised class of disturbance of left ventricular wall motion is that involving abnormalities of timing (incoordination). Such abnormalities are subtle and easily overlooked on simple inspection of the conventional $M$ mode or cross sectional echocardiogram but may be readily identified

\footnotetext{
Requests for reprints to Dr G C Sutton, Cardiac Department, Hillingdon Hospital, Uxbridge, Middlesex UB8 3NN.

^Present address: Department of Cardiology, St Thomas' Hospital, London, SE1 7EH.

Accepted for publication 1 December 1983
}

when $M$ mode echocardiograms recorded simultaneously with a phonocardiogram and apexcardiogram are analysed using a digitising technique. Shortening of the time interval between aortic valve closure $\left(A_{2}\right)$ and minimum cavity dimension ${ }^{5}$ and abnormal left ventricular dimension change during the period of inscription of the upstroke of the apexcardiogram ${ }^{6}$ and during isovolumic relaxation ${ }^{7}$ are indices which when identified imply incoordinate left ventricular wall motion during early systole and early diastole.

We made serial recordings of simultaneous $M$ mode echocardiograms, phonocardiograms, and apexcardiograms in 20 patients with an acute myocardial infarction and analysed them using the digitising method to identify incoordinate left ventricular wall motion. Our aims were $(a)$ to determine the incidence of incoordinate left ventricular wall motion after myocardial infarction, $(b)$ to record its evolution, and 
(c) to establish its relation with the clinical state of the patient.

\section{Patients and methods}

Twenty patients (16 men, four women; age range 32-75 (mean 54) years) admitted to hospital with severe chest pain but without a previous history of myocardial infarction were studied. These were patients in whom an echocardiogram and apexcardiogram of a high technical quality could be recorded. All patients had serial increases in cardiac enzyme activity and had electrocardiographic abnormalities which confirmed the diagnosis of acute myocardial infarction. Clinical details are shown in Table 1. A full thickness infarction was defined as the development of $Q$ waves in the electrocardiogram that persisted throughout follow up. A partial thickness infarction was defined as $T$ wave abnormalities (without the development of $Q$ waves) which usually reverted towards normal during recovery. Heart failure was considered to complicate the episode of infarction if the patient complained of breathlessness and had the radiological features of pulmonary venous congestion and pulmonary oedema. All patients, except one who died of ventricular fibrillation at 11 days, survived for 56 days after an acute infarction.

\section{RECORDING TECHNIQUES}

Simultaneous echocardiograms, apexcardiograms, phonocardiograms, and electrocardiograms were recorded with the patient in the left semilateral position. Echocardiograms were recorded with a Smith
Kline Ekoline 20 ultrasonoscope using a $2.25 \mathrm{MHz}$ transducer. Clear continuous recordings of the left ventricular septal and posterior wall endocardium at the level of mitral valve were obtained. Apexcardiograms were obtained using a Cambridge Scientific Instruments transducer with a four second time constant and a lower frequency limit of $0.04 \mathrm{~Hz}$. All apex cardiograms had a well defined $C$ point (the inflection at the start of the upstroke) and $\mathrm{E}$ point (the point marking discontinuation of the rapidly rising portion of the upstroke). Phonocardiograms were obtained using a Cambridge Leatham microphone with a high frequency filter positioned at the base of the heart where splitting of the second heart sound was most obvious clinically. Tracings were made photographically using a Cambridge multichannel recorder at a paper speed of $100 \mathrm{~mm} / \mathrm{s}$ (Fig. 1).

Initial recordings were made between six and 12 hours after the onset of chest pain and subsequent measurements were made two, three, seven, and 56 days after infarction. In three patients on day 2 , one patient on day 7, and two patients on day 56 the recordings obtained were not of sufficient technical quality and were therefore excluded from further analysis.

Recordings were digitised ${ }^{8}$ and plots obtained showing the original data, the continuous left ventricular dimension with time, the rate of change of dimension with time normalised to refer to unit length of dimension, and an apexcardiogram-left ventricular dimension loop (Fig. 2).

From the recordings made on each day, two separate cardiac cycles were analysed and the following

Table 1 Clinical data for the 20 study patients

\begin{tabular}{|c|c|c|c|c|c|c|c|}
\hline \multirow{2}{*}{$\begin{array}{l}\text { Case } \\
\text { No }\end{array}$} & \multirow[t]{2}{*}{ Sex } & \multirow{2}{*}{$\begin{array}{l}\text { Age } \\
\text { (yr) }\end{array}$} & \multirow{2}{*}{$\begin{array}{l}\text { Infarct } \\
\text { position }\end{array}$} & \multirow{2}{*}{$\begin{array}{l}\text { Infarct } \\
\text { type }\end{array}$} & \multicolumn{2}{|c|}{ Maximum cardiac encyme activity } & \multirow[t]{2}{*}{ Heart failure } \\
\hline & & & & & $\alpha-H B D H(I U / l)$ & $A S T(I U / l)$ & \\
\hline $\begin{array}{r}1 \\
2 \\
3 \\
4 \\
5 \\
6 \\
7 \\
8 \\
9 \\
10 \\
11 \\
12 \\
13 \\
14 \\
15 \\
16 \\
17 \\
18 \\
19 \\
20\end{array}$ & $\begin{array}{l}\mathbf{F} \\
\mathbf{M} \\
\mathbf{M} \\
\mathbf{M} \\
\mathbf{M} \\
\mathbf{M} \\
\mathbf{F} \\
\mathbf{M} \\
\mathbf{M} \\
\mathbf{M} \\
\mathbf{M} \\
\mathbf{M} \\
\mathbf{M} \\
\mathbf{M} \\
\mathbf{F} \\
\mathbf{M} \\
\mathbf{M} \\
\mathbf{F} \\
\mathbf{M} \\
\mathbf{M}\end{array}$ & $\begin{array}{l}34 \\
68 \\
79 \\
39 \\
59 \\
59 \\
62 \\
60 \\
40 \\
40 \\
55 \\
33 \\
47 \\
66 \\
52 \\
44 \\
58 \\
47 \\
58 \\
49\end{array}$ & $\begin{array}{l}\text { ANT } \\
\text { ANT } \\
\text { ANT } \\
\text { ANT } \\
\text { INF } \\
\text { INF } \\
\text { ANT } \\
\text { ANT } \\
\text { ANT } \\
\text { ANT } \\
\text { ANT } \\
\text { INF } \\
\text { INF } \\
\text { ANT } \\
\text { INF } \\
\text { ANT } \\
\mathbf{A N T} \\
\mathbf{A N T} \\
\mathbf{A N T} \\
\mathbf{A N T}\end{array}$ & $\begin{array}{l}\text { FT } \\
\text { FT } \\
\text { FT } \\
\text { PT } \\
\text { FT } \\
\text { FT } \\
\text { FT } \\
\text { PT } \\
\text { FT } \\
\text { FT } \\
\text { PT } \\
\text { FT } \\
\text { PT } \\
\text { FT } \\
\text { PT } \\
\text { FT } \\
\text { PT } \\
\text { FT } \\
\text { FT } \\
\text { FT }\end{array}$ & $\begin{array}{r}780 \\
970 \\
306 \\
255 \\
796 \\
409 \\
1070 \\
164 \\
598 \\
1217 \\
382 \\
778 \\
382 \\
990 \\
385 \\
378 \\
249 \\
1426 \\
936 \\
921\end{array}$ & $\begin{array}{r}160 \\
159 \\
147 \\
50 \\
207 \\
28 \\
172 \\
30 \\
122 \\
280 \\
98 \\
215 \\
99 \\
61 \\
70 \\
128 \\
45 \\
162 \\
245 \\
207\end{array}$ & $\begin{array}{l}+ \\
+ \\
+\end{array}$ \\
\hline
\end{tabular}

$\alpha$-HBDH, $\alpha$-hydroxybutyrate dehydrogenase (normal range 70-150 IU/); AST, aspartate aminotransferase (normal range 2-18 IU/); ANT, anterior infarction; INF, inferior infarction; FT, full thickness infarction; PT, partial thickness infarction.

$\star$ Died during follow up 


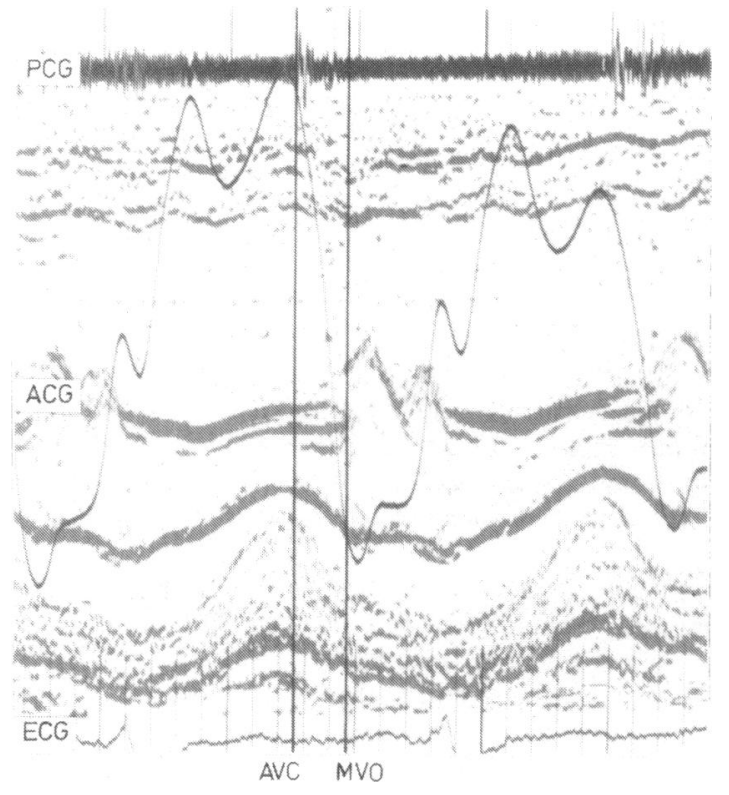

Fig. 1 Echocardiogram taken on day 3 from a patient with an anterior infarction showing left ventricular septal and posterior wall endocardium and the mitral valve cusps recorded together with an electrocardiogram (ECG), phonocardiogram (PCG), and apexcardiogram (ACG). $A V C$, aortic valve closure; $M V O$, mitral valve opening.

measurements made: $(a)$ left ventricular maximum and minimum dimensions; (b) heart rate; (c) isovolumic relaxation time- that is, aortic valve closure (taken as the onset of the first high frequency vibration of the second heart sound identified from the phonocardiogram) to mitral valve opening (determined from the echocardiogram as the point of initial separation of the mitral valve cusps); $(d)$ indices of coordinate left ventricular wall motion during early diastole: (i) $A_{2}$ to minimum cavity dimensions (defined as the point where the derivative of cavity dimension changes from negative to positive); (ii) left ventricular cavity dimension change during isovolumic relaxation ${ }^{7}$ (expressed as a percentage of the total change in dimension during the cardiac cycle) and during early systole; (iii) left ventricular cavity dimension change during the upstroke of the apexcardiogram 6 - that is, the time interval between the $\mathrm{C}$ point and $\mathrm{E}$ point (approximating to isovolumic contraction) expressed in the same fashion as (ii); (e) peak systolic rate of decrease in dimension (peak velocity of circumferential fibre shortening (per s); and $(f)$ peak diastolic rate of increase in dimension (per s).

\section{DATA ANALYSIS}

Initial analysis was carried out by considering patients as a single group. Later separate subgroups were

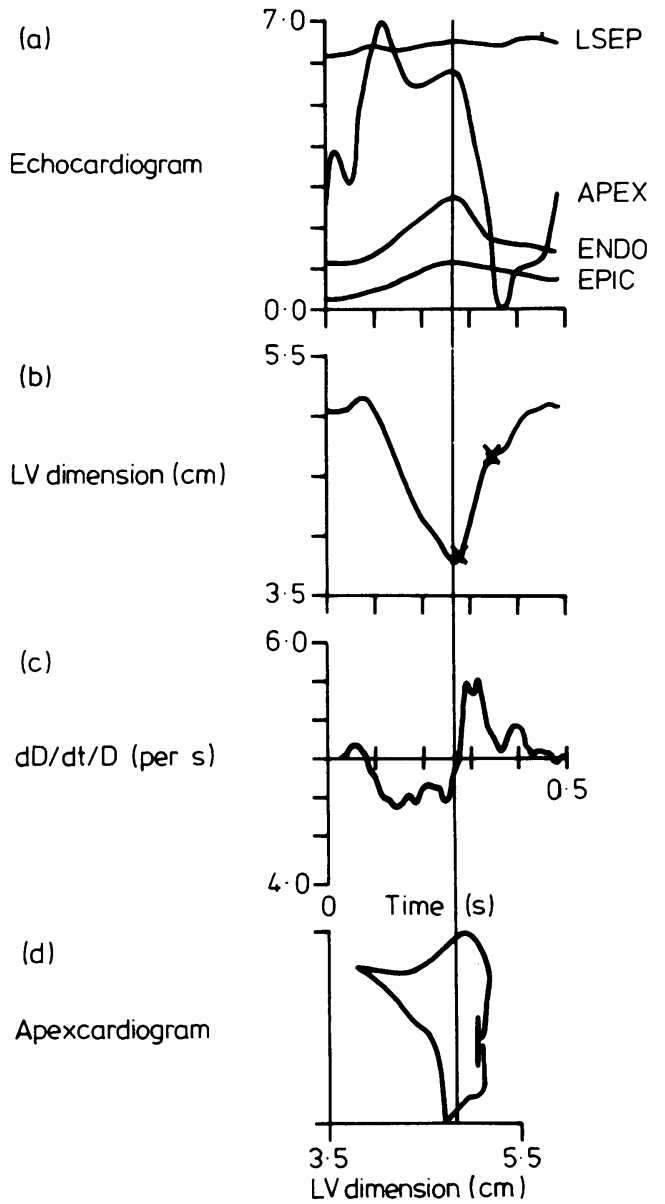

Fig. 2 Computer output of the digitised tracing obtained from the recording in Fig. I showing (a) the original data, (b) left ventricular $(L V)$ dimension, $(c)$ rate of change of dimension normalised to refer to unit length of dimension $(d D / d t / D)$, and $(d)$ an apexcardiogram-left ventricular dimension loop. The vertical line indicates the timing of minimum cavity dimension. The two crosses (b) show the timing of aortic valve closure and mitral value opening. LSEP, septal endocardium; $A P E X$, apex cardiogram; ENDO, endocardium; EPIC, epicardium.

defined, based on (a) the site of infarction, $(b)$ the type of infarction (full or partial thickness), and (c) the presence or absence of clinical heart failure.

Results were expressed as mean \pm SEM. Statistical method was by analysis of variance. The $Z$ test was used to compare results with previously established normal values. Linear regression analysis was used to measure correlation between variables. 
Results

\section{ALL PATIENTS}

Detailed results for the group as a whole are shown in Table 2 and Fig. 3, which also contain, for comparative purposes, normal values derived from previously published data. 69

Throughout the study left ventricular maximum and minimum dimensions remained within the normal range. Heart rate was highest in the first three days after infarction. Isovolumic relaxation time on admission was prolonged $(p<0.001)$ and did not change during the study. Peak velocity of circumferential fibre shortening was within the normal range immediately after infarction but fell with time and by day 56 was abnormally low $(\mathrm{p}<0.01)$. Peak rate of dimension increase during diastole was reduced on admission from normal $(p<0.001)$ and remained unchanged throughout the study.

Incoordinate wall motion was present in all patients. In normal subjects aortic valve closure $\left(\mathbf{A}_{\mathbf{2}}\right)$ is constantly related to minimum cavity dimension with $\mathrm{A}_{2}$ preceding the latter by $50 \pm 15 \mathrm{~ms} .{ }^{9}$ This time relation was distorted in patients after infarction. The greatest abnormalities were evident in the first three days after infarction with, in many patients, $A_{2}$ occurring not before but after minimum cavity dimension. With time, values tended to regress towards normal (Fig. 3a). Similarly left ventricular dimension change during isovolumic relaxation was also appreciably abnormal on admission and showed a similar pattern of partial return towards normal (Fig. 3a). Left ventricular dimension change during the upstroke of the apexcardiogram was also abnormal on admission but, in contrast to the other two indices of coordinate wall motion, showed no tendency to return to normal during follow up (Fig. 3a).

\section{SITE OF INFARCTION}

Throughout the study there was no relation between the site of infarction and maximum or minimum left ventricular dimensions, duration of isovolumic relaxation, peak velocity of circumferential fibre shortening, or peak rate of dimension increase during diastole.

Heart rate was higher in patients with anterior infarcts $(n=15)$ than in those with inferior infarcts $(n=5)(p<0.01)$ reflecting the presence of heart failure in some patients with anterior infarctions.

Fig. 3b compares the two groups with respect to incoordinate left ventricular wall motion. Early diastolic abnormalities were significantly greater in patients with anterior infarcts than in those with inferior infarcts. In contrast abnormal left ventricular dimension changes during the period of the upstroke of the apexcardiogram were similar in each group.

\section{TYPE OF INFARCTION}

Fourteen patients had full thickness infarctions and six partial thickness infarctions, (Fig. 3c). In the first two days after infarction these two groups were indistinguishable except with respect to heart rate, which was higher in patients with full thickness infarctions. Nevertheless, differences became apparent during further follow up: at $\mathbf{5 6}$ days after infarction, there were differences between patients with full and partial thickness infarcts in left ventricular maximum dimension $(5.6 \pm 0.2 \mathrm{~cm}$ and $4.5 \pm 0.3 \mathrm{~cm}$ respectively; p $<0.01$ ), left ventricular minimum dimension $(4.1 \pm 0.2 \mathrm{~cm}$ and $2.9 \pm 0.2 \mathrm{~cm}$ respectively; $\mathrm{p}<0.01)$, and peak velocity of circumferential fibre shortening $(1.9 \pm 0.2$ and $2.7 \pm 0.9$ respectively; $p<0.05)$ but not in isovolumic relaxation time or peak rate of dimension increase during diastole.

In patients with partial thickness infarcts, the three indices of coordinate left ventricular wall motion that were initially abnormal each regressed almost completely to normal values, whereas in those patients with full thickness infarcts, although partial regression was observed, there were considerable residual abnormalities (Fig. 3c).

Table 2 Serial measurements of left ventricular maximum and minimum dimensions, peak velocity of circumferential fibre shortening, normalised peak rate of dimension increase during diastole, isovolumic relaxation time, and heart rate in the 20 study patients. Values are means $\pm S E M$

\begin{tabular}{|c|c|c|c|c|c|c|}
\hline & \multicolumn{5}{|c|}{ Days after infarction } & \multirow{2}{*}{$\begin{array}{l}\text { Normal range } \\
(\text { mean } \pm S D)\end{array}$} \\
\hline & 1 & 2 & 3 & 7 & 56 & \\
\hline \multicolumn{7}{|c|}{ Left ventricular dimension $(\mathrm{cm})$} \\
\hline $\begin{array}{l}\text { Maximum } \\
\text { Minimum }\end{array}$ & $\begin{array}{l}4 \cdot 8 \pm 0.1 \\
3 \cdot 3 \pm 0.1\end{array}$ & $\begin{array}{l}4 \cdot 6 \pm 0 \cdot 1 \\
3 \cdot 2 \pm 0 \cdot 1\end{array}$ & $\begin{array}{l}5 \cdot 0 \pm 0.1 \\
3 \cdot 5 \pm 0.1\end{array}$ & $\begin{array}{l}5.2 \pm 0.3 \\
3.5 \pm 0.1\end{array}$ & $\begin{array}{l}5 \cdot 3 \pm 0.1 \\
3.6 \pm 0.2\end{array}$ & $\begin{array}{l}5 \cdot 0 \pm 0.5 \\
3 \cdot 1 \pm 0.5\end{array}$ \\
\hline $\begin{array}{l}\text { Peak velocity of circumferential } \\
\text { fibre shortening } \\
\text { Peak dimension increase (per s) } \\
\text { Isovolumic relaxation time (ms) } \\
\text { Heart rate (beats/min) }\end{array}$ & $\begin{array}{l}2 \cdot 5 \pm 0 \cdot 1 \\
4 \cdot 1 \pm 0 \cdot 3^{\star} \\
80 \cdot 0 \pm 4^{\star} \\
82 \cdot 0 \pm 3\end{array}$ & $\begin{array}{l}2 \cdot 6 \pm 0 \cdot 1 \\
4 \cdot 2 \pm 0 \cdot 2^{\star} \\
84 \cdot 0 \pm 3^{\star} \\
93 \cdot 0 \pm 3\end{array}$ & $\begin{array}{l}2 \cdot 4 \pm 0 \cdot 1 \\
4 \cdot 2 \pm 0 \cdot 3^{\star} \\
85 \cdot 0 \pm 4^{\star} \\
89 \cdot 0 \pm 4\end{array}$ & $\begin{array}{l}2 \cdot 4 \pm 0 \cdot 1 \\
4 \cdot 0 \pm 0 \cdot 2^{\star} \\
76 \cdot 0 \pm 4^{\star} \\
79 \cdot 0 \pm 3\end{array}$ & $\begin{array}{l}2 \cdot 1 \pm 0 \cdot 1^{\star \star} \\
4 \cdot 2 \pm 0 \cdot 2^{\star} \\
77 \cdot 0 \pm 3^{\star} \\
77 \cdot 0 \pm 3\end{array}$ & $\begin{array}{l}2 \cdot 5 \pm 0 \cdot 6 \\
5 \cdot 7 \pm 1 \cdot 7 \\
65 \cdot 0 \pm 15\end{array}$ \\
\hline
\end{tabular}

${ }^{\star} \mathrm{p}<0.001 ;{ }^{\star \star} \mathrm{p}<0.01$ (comparison with normal range). 

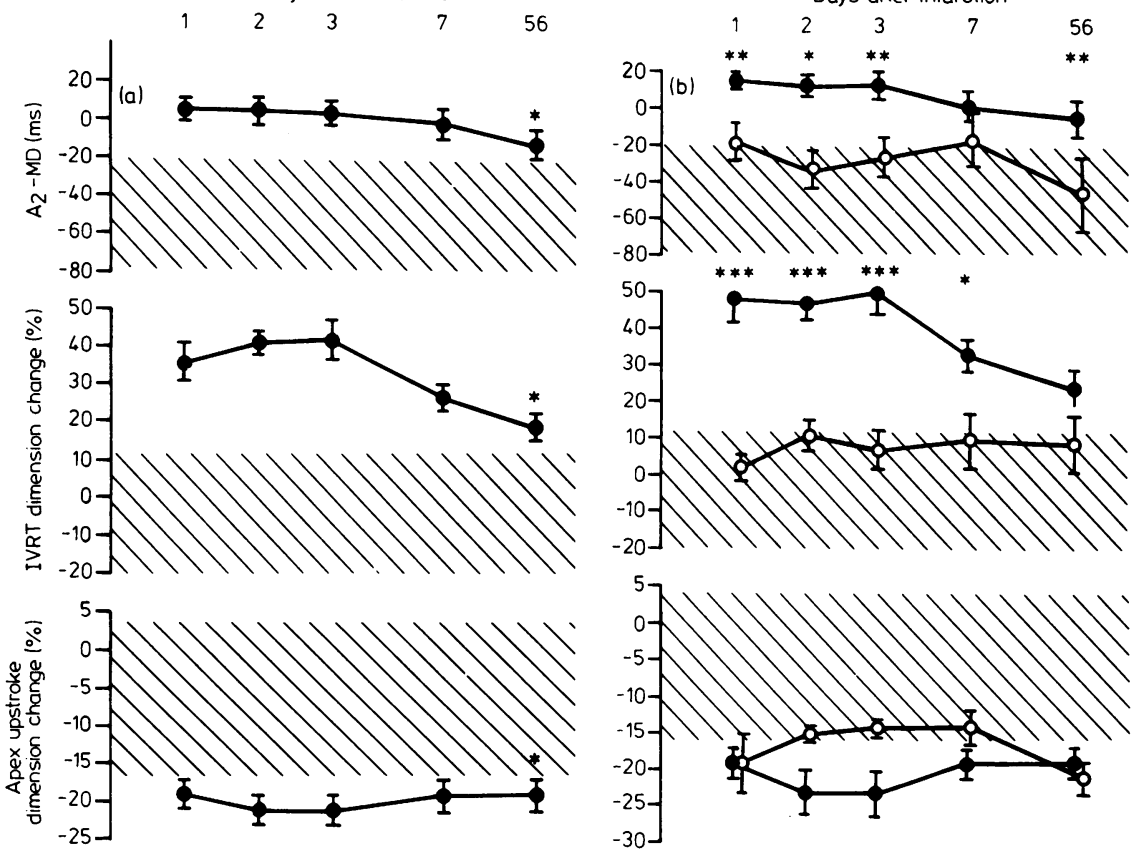

$-30$

Fig. 3 Serial mean $\pm S E M$ values for three indices of coordinate lefi ventricular wall motion: $A_{2}$ to minimum cavity dimension (MD), lefi ventricular dimension change during isovolumic relaxation (IVRT) and left ventricular dimension change (\%) during the upstroke of the apexcardiogram. The shaded areas in each panel represent the $95 \%$ confidence limits of the normal range for each index derived from previously published data. (a) shows the results for all 20 patients studied ( ${ }^{\star} p<0.001$ comparison with normal values); (b) shows the results for the 15 patients with an anterior infarct $(\bullet)$ and the five with an inferior infarct $(O)$

$\left({ }^{\star} p<0.05 ; \star \star p<0.01 ; \star \star \star p<0.001\right.$; comparison between groups); (c) shows the results in the 14 patients with a full thickness infarct $(\bullet)$ and the six with a partial thickness infarct $(O)(\star p<0.01$; $\star \star p<0.001$; comparison between groups); and $(d)$ shows the results in the seven patients with $(O)$ and the 13 without $(\circlearrowleft)$ heart failure complicating acute infarction $\left({ }^{\star} p<0.05\right.$; comparison between groups). 
PRESENCE OF HEART FAILURE

Clinical evidence of heart failure complicated acute myocardial infarction in seven of the 20 patients studied. In the first three days after infarction, patients with heart failure were indistinguishable echocardiographically from those without except that heart rate was higher $(p<0.05)$. Left ventricular maximum and minimum dimensions were not increased acutely in those patients with heart failure, and the indices of coordinate left ventricular wall motion were abnormal to a comparable degree in the two groups (Fig. 3d). Again, differences were apparent by 56 days after infarction. When heart failure had been present both maximum $(5.9 \pm 0.3 \mathrm{~cm})$ and minimum $(4.4 \pm 0.4 \mathrm{~cm})$ left ventricular dimensions were increased $(p<0.05)$ compared with those without heart failure $(5.0 \pm 0.3 \mathrm{~cm}$ and $3.3 \pm 0.3 \mathrm{~cm}$ respectively), and evidence of incoordinate left ventricular wall motion was more pronounced (Fig. 3d).

\section{CARDIAC ENZYMES}

In the group overall the mean values for peak serum $\alpha$-hydroxybutyrate dehydrogenase and aspartate aminotransferase activities were $670 \pm 82$ IU/A and $134 \pm 17$ IU/1 respectively; in patients with anterior infarcts the respective values were $709 \pm 104$ IU/1 and $138 \pm 19 \mathrm{IU} / \mathrm{A}$, and in patients with inferior infarcts $550 \pm 97 \mathrm{IU} / 1$ and $124 \pm 37 \mathrm{IU} / 1$. In patients with full thickness infarcts the respective values were $827 \pm 86$ $\mathrm{IU} / 1$ and $164 \pm 18 \mathrm{IU} / \mathrm{h}$, and in patients with partial thickness infarcts $303 \pm 38$ IU/ $/$ and $65 \pm 12$ IU $/$. In patients with heart failure, the respective values were $958 \pm 134 \mathrm{IU} / \mathrm{h}$ and $189 \pm 19 \mathrm{IU} / \mathrm{I}$ and in uncomplicated infarcts $514 \pm 76 \mathrm{IU} / \mathrm{A}$ and $105 \pm 19 \mathrm{IU} / 1$.

Previous studies ${ }^{10}$ have shown that in patients with acute myocardial infarction the maximum activity of serum $\alpha$-hydroxybutyrate dehydrogenase and aspartate aminotransferase is closely correlated with estimates of the size of infarction derived from serial creatinine phosphokinase determinations and the clinical and haemodynamic status of the patients. We thus used the maximal activity of serum $\alpha$-hydroxybutyrate dehydrogenase and aspartate aminotransferase as an estimate of infarct size in individual patients. During the first three days after infarction there was no correlation between estimates of infarct size so derived and any of the measurements of left ventricular function. Fifty six days after infarction a correlation was found between the estimates of infarct size and left ventricular maximum dimension ( $\alpha$-hydroxybutyrate dehydrogenase, $r=0.7$; aspartate aminotransferase, $r=0.58 ; p<0.01$ ), left ventricular minimum dimension $(r=0.77$ and 0.58 respectively; $\mathrm{p}<0.001$ ) and peak velocity of circumferential fibre shortening $(r=0.62$ and 0.56 respectively; $p<0.001)$. No correlation was found between the enzyme esti- mates of infarct size and the magnitude of abnormalities of the three indices of coordinate left ventricular wall motion either immediately after infarction or during follow up.

\section{Discussion}

Numerous echocardiographic studies using both $M$ mode and cross sectional techniques have been performed in patients with acute myocardial infarction. ${ }^{1-411-18}$ In the majority of these studies reduced amplitude of endocardial motion (asynergy) has been used as the hallmark identifying regional abnormalities of left ventricular wall motion. Although the resolution of $M$ mode echocardiography is such that precise definition of the position of the endocardium throughout the cardiac cycle can be obtained, ${ }^{19}$ in the assessment of asynergy the narrow ultrasound beam has the major disadvantage of visualising only a small segment of the left ventricle. Thus in some patients with acute myocardial infarction the presence of asynergy may not be observed." The sensitivity of $M$ mode in detecting asynergy may be increased by using multiple views, 1112 but this method and its analysis have the disadvantage of being complex and time consuming.

Because it enables the entire left ventricle to be visualised cross sectional echocardiography is in general more successful than $M$ mode in detecting asynergy; however, the resolution of the technique does not always allow precise identification of the endocardial position. ${ }^{20}$ In addition, the definition of asynergy lacks standard criteria and usually analysis of wall motion depends on a subjective semiquantitative approach. ${ }^{21}$

The ability of $M$ mode echocardiography to detect abnormal left ventricular wall motion is enhanced when phonocardiograms and apexcardiograms are recorded simultaneously and the results digitised. Abnormalities of timing of endocardial motion (incoordination) can then be identified even when there is normal amplitude of endocardial motion in the portion of the left ventricle transected by the ultrasound beam. The three measurements used in this study-abnormalities of which reflect incoordinate left ventricular wall motion during early systole and early diastole-have been validated by comparison with frame by frame analysis of left ventricular cineangiograms in patients with asynergic left ventricles. 57

The patients in this study were not matched for age or any other variable with the populations providing "normal" values. It must, therefore, be emphasised that significant differences from normal in our patients may not only have been due to the presence of acute myocardial infarction. Separation of the 
patients with respect to infarct position or type or the clinical presence of heart failure has produced small subgroups which still remain heterogeneous in composition. The results of comparisons between subgroups, therefore, must be viewed cautiously to avoid the danger of overinterpretation of data.

In this study, in patients with acute myocardial infarction, assessment of timing of endocardial movement using the digitising technique permitted abnormal left ventricular wall motion to be detected in all patients, a result comparable with the results of studies based on cross sectional echocardiography ${ }^{3} 13$ and superior to previous $M$ mode echocardiographic studies detecting asynergy. 12 Serial evaluation showed that these abnormalities were maximal in the first three days after infarction and then tended to regress towards normal during further follow up.

Abnormal left ventricular wall motion was found both in patients with anterior and inferior infarcts, but the pattern of abnormality of the three measurements of coordination differed between the two groups. In patients with inferior infarctions only the measurement of left ventricular dimension change during the period of upstroke of the apexcardiogram was abnormal whereas in those patients with anterior infarcts all three measurements of coordination were abnormal. This finding has no definite explanation and may have been due to chance; those patients with inferior infarcts comprised a small group who differed from those with anterior infarcts in having smaller (as defined by mean maximal rise in cardiac enzyme activity) uncomplicated infarcts.

Heart failure complicated acute myocardial infarction in seven of the 20 patients in this study. These seven patients had significantly larger infarcts, estimated by maximal activity of cardiac enzymes, than those without heart failure $(p<0.001)$. In the first three days after myocardial infarction, however, there were no significant differences with respect to the three measurements of coordinate left ventricular wall motion between patients with and without heart failure. This implies that incoordinate left ventricular wall motion detected by the digitising technique is not quantitatively related to infarct size and hence cannot be used to estimate prognosis. By contrast, cross sectional echocardiographic studies by analysing the extent of asynergy have claimed to estimate infarct size and thus predict prognosis. ${ }^{417}$ Nevertheless, animal studies have shown that the extent of asynergy detected by cross sectional echocardiography after experimental coronary artery occlusion is not necessarily related to infarct size. ${ }^{22-24}$ Asynergy occurs in areas of myocardium with reversible ischaemia ${ }^{25}$ and may also occur in normal non-ischaemic myocardium as a result of "tethering" to adjacent ischaemic myocardium. ${ }^{26}$ The results of these animal studies showing poor correlation between quantification of left ventricular wall motion abnormalities and the actual size of the myocardial infarction are in accordance with our $M$ mode echocardiographic observations. A clinical study in man which failed to show a relation between the cineangiographic site and the extent of asynergy in life with postmortem histological evidence of infarction also supports our findings. ${ }^{27}$

In this study in patients without a previous history of myocardial infarction the echocardiographic determination of left ventricular dimension in the first three days after infarction failed to distinguish between those patients with and those without heart failure. This contrasts with the findings of several previous echocardiographic studies ${ }^{18}$ but is in accordance with the findings of others who, ${ }^{216}$ like us, found no increase in left ventricular dimensions acutely in patients with heart failure complicating myocardial infarction. Further evaluation at 56 days in our patients did show a significant increase in both maximum and minimum left ventricular dimensions in those patients in whom heart failure complicated the acute infarct, a finding which confirmed physiological expectations.

Six patients in this study were identified as having a partial thickness or subendocardial infarction. Incoordinate left ventricular wall motion was detected in all, a finding which contrasts with the results of cross sectional echocardiography, which may not identify asynergy at all in this group of patients. ${ }^{17}$ Indeed in the first two days after infarction there were no differences between patients with full and those with partial thickness infarcts with respect to the extent of left ventricular incoordination, as judged by the three indices, despite the much larger enzymatically estimated infarct size of patients with full thickness infarcts $(p<0.001)$. Nevertheless, striking differences became apparent during further follow up. In patients with partial thickness infarcts the initially abnormal indices of coordinate left ventricular wall motion returned to normal, whereas in patients with full thickness infarction considerable abnormalities remained although partial regression was observed. This finding is in accordance with cineangiographic observations in patients with a previous myocardial infarction in which a full thickness infarction is associated with residual asynergy (due to scarring), whereas in patients with well documented previous partial thickness infarction left ventricular wall motion may be normal. Thus the method used in this study, although very sensitive in its ability to detect incoordinate left ventricular wall motion in the acute phase of myocardial infarction, cannot discriminate acutely between abnormal wall motion which is the result of infarction leading to permanent scarring and abnormal wall motion which is, presumably, the 
result of mainly reversible ischaemia. The results show, however, that a retrospective separation of full thickness infarcts, producing tissue death and scarring, from partial thickness infarcts, causing transient ischaemia, can be made if initially abnormal left ventricular wall motion becomes normal in serial studies. A similar reversion of incoordinate left ventricular wall motion to coordinate wall motion has been observed in patients after aortic valve replacement, ${ }^{28}$ changes probably attributable to reversible ischaemia occurring with cardiopulmonary bypass.

The results of this study have several clinical implications. The detection and serial evaluation of incoordinate left ventricular wall motion may be a useful diagnostic indicator in those patients admitted to hospital with chest pain in whom the electrocardiogram and measurement of cardiac enzyme activity are unhelpful in determining if myocardial ischaemia has occurred. By allowing the non-invasive detection of reversible myocardial ischaemia serial studies may identify a group of postinfarction patients in whom there is residual jeopardised myocardium and who may have a high incidence of subsequent myocardial infarction or sudden death.

Finally, our observations suggest that left ventricular wall motion and function in the acute phase after myocardial infarction cannot adequately be described by a single echocardiographic measurement or derived index. We thus advocate caution in using echocardiography to make early estimates of infarct size, and hence assessment of prognosis, in patients with acute myocardial infarction.

We thank Mr Richard Morris, Department of Community Medicine, St Thomas's Hospital, for his advice on the statistical analysis of the results.

\section{References}

1 Corya BC, Rasmussen S, Knoebel SB, Feigenbaum H. Echocardiography in acute myocardial infarction. Am $\mathcal{f}$ Cardiol 1975; 36: 1-10.

2 Broder MI, Cohn JN. Evolution of abnormalities in left ventricular function after acute myocardial infarction. Circulation 1972; 46: 731-43.

3 Heger JJ, Weyman AE, Wann LS, Dillon JC, Feigenbaum H. Cross-sectional echocardiography in acute myocardial infarction: detection and localization of regional left ventricular asynergy. Circulation 1979; 60: 531-8.

4 Eaton LW, Weiss JL, Bulkley BH, Garrison JB, Weisfeldt ML. Regional cardiac dilatation after acute myocardial infarction: recognition by two-dimensional echocardiography. $N$ Engl $\mathcal{F}$ Med 1979; 300: 57-62.

5 Chen W, Gibson DG. Relation of isovolumic relaxation to left ventricular wall movement in man. Br Hear $\mathcal{f} 1979 ; 42: 51-6$.

6 Doran JH, Traill TA, Brown DJ, Gibson DG. Detection of abnormal left ventricular wall movement during isovolumic contraction and early relaxation. Comparison of echo- and angiocardiography. Br Hear $\mathcal{f}$ 1978; 40: 367-71.

7 Gibson DG, Doran JH, Traill TA, Brown DJ. Regional abnormalities of left ventricular wall movement during isovolumic relaxation in patients with ischemic heart disease. Eur $\mathcal{f}$ Cardiol 1978; 7 (suppl): 251-64.
8 Gibson DG, Brown D. Measurement of instantaneous left ventricular dimension and filling rate in man, using echocardiography. Br Heart $\mathcal{f}$ 1973; 35: 1141-9.

9 Dawson JR, Sutton GC. Detection of clinically significant coronary artery disease in hypertensive patients. Echocardiographic study. Br Heart f 1981; 46: 595-602.

10 Mathey D, Bleifeld W, Hanrath P, Effert S. Attempt to quantitate relation between cardiac function and infarct size in acute myocardial infarction. $\mathrm{Br}$ Hear $\mathcal{f} 1974$; 36: 271-9.

11 Heikkill J, Nieminen M. Echoventriculographic detection, localization, and quantification of left ventricular asynergy in acute myocardial infarction. A correlative echo- and electrocardiographic study. Br Heart f 1975; 37: 46-59.

12 Nieminen M, Heikkila J. Echoventriculography in acute myocardial infarction. III. Clinical correlations and implication of the non-infarcted myocardium. Am $\mathcal{f}$ Cardiol 1976; 38: 1-8.

13 Heger JJ, Weyman AE, Wann LS, Rogers EW, Dillon JC, Feigenbaum H. Cross-sectional echocardiographic analysis of the extent of left ventricular asynergy in acute myocardial infarction. Circulation 1980; 61: 1113-8.

14 Visser CA, Lie KI, Kan G, Meltzer R, Durrer D. Detection and quantification of acute, isolated myocardial infarction by two dimensional echocardiography. Am f Cardiol 1981; 47: 1020-5.

15 Wynne J, Birnholz J, Finberg H, Alpert JS. Regional left ventricular wall motion in acute myocardial infarction as assessed by two dimensional echocardiography [Abstract]. Circulation 1977; 56 (suppl III): 152.

16 Smith M, Ratshin RA, Harrell FE Jr, Russell RO Jr, Rackley CE. Early sequential changes in left ventricular dimensions and filling pressure in patients after myocardial infarction. Am $f$ Cardiol 1974; 33: 363-9.

17 Bloch A, Morard JD, Mayor C, Perrenoud JJ. Cross-sectional echocardiography in acute myocardial infarction [Abstract]. Am $\mathcal{F}$ Cardiol 1979; 43: 387.

18 DeMaria AN, Angel J, Amsterdam EA, Mason DT. Accurate assessment of extent and prognosis in acute myocardial infarction by echocardiographic index of ejection fraction and ventricular volume: close correlation with cardiac catheterization determined stroke work [Abstract]. Am $\mathcal{f}$ Cardiol 1976; 37: 131.

19 Feigenbaum H. Echocardiography. 2nd ed. Philadelphia: Lea and Febiger, 1976: 292-5, 313-7.

20 Meister SG, Casey PR, Jacobs L, Barrett MJ. 2-D Echo definition of endocardium [Abstract]. Circulation 1980; 62 (suppl III): 132.

21 Falsetti HL, Marcus ML, Kerber RE, Skorton DJ. Quantification of myocardial ischemia and infarction by left ventricular imaging. [Editorial]. Circulation 1981; 63: 747-51.

22 Lieberman AN, Weiss JL, Jugdutt BI, et al. Two-dimensional echocardiography and infarct size: relationship of regional wall motion and thickening to the extent of myocardial infarction in the dog. Circulation 1981; 63: 739-46.

23 Heng MK, Lang TW, Toshimitsu T, et al. Quantification of myocardial ischemic damage by two-dimensional echocardiography [Abstract]. Circulation 1977; 55 (suppl III): 125.

24 Weyman AE, Franklin TD, Egenes KM, Green D. Correlation between the extent of abnormal regional wall motion and myocardial infarct size in chronically infarcted dogs [Abstract]. Circulation 1977; 55 (suppl III): III-72.

25 Wyatt HL, Forrester JS, daLuz PL, Diamond GA, Chagrasulis $R$, Swan HJC. Functional abnormalities in non-occluded regions of myocardium after experimental coronary occlusion. Am $\mathcal{f} \mathrm{Car}-$ diol 1976; 37: 366-72.

26 Kerber RE, Marcus ML, Ehrhardt J, Wilson R, Abboud FM. Correlation between echocardiographically demonstrated segmental dyskinesis and regional myocardial perfusion. Circulation 1975; 52: 1097-104.

27 Hutchins GM, Bulkley BH, Ridolfi RL, Giffith LSC, Lohr FT, Piasio MA. Correlation of coronary arteriograms and left ventriculograms with post-mortem studies. Circulation 1977; 56: 32-7.

28 Venco A, St. John Sutton MG, Gibson DG, Brown DJ. Noninvasive assessment of left ventricular function after correction of severe aortic regurgitation. Br Heart $\mathcal{f}$ 1976; 38: 1324-31. 